\title{
Characteristics of the Paediatric Foot Arches According to Body Mass Among Primary School Students in Wrocław, Poland
}

\section{Sara Górna}

Akademia Wychowania Fizycznego im Eugeniusza Piaseckiego w Poznaniu

Katarzyna Pazdro-Zastawny ( $\square$ kasiapz@poczta.fm )

Wroclaw Medical University: Uniwersytet Medyczny im Piastow Slaskich we Wroclawiu https://orcid.org/0000-0001-8056-1198

Alicja Basiak-Rasała

Uniwersytet Medyczny im Piastów Śląskich we Wrocławiu: Uniwersytet Medyczny im Piastow Slaskich we Wroclawiu

\section{Mateusz Kolator}

Wroclaw Medical University: Uniwersytet Medyczny im Piastow Slaskich we Wroclawiu

Joanna Krajewska

Wroclaw Medical University: Uniwersytet Medyczny im Piastow Slaskich we Wroclawiu

Tomasz Zatoński

Wroclaw Medical University: Uniwersytet Medyczny im Piastow Slaskich we Wroclawiu; "Run for Helath" Foundation "

\section{Research Article}

Keywords: longitudinal, transverse children's foot arch, Health Foundation, anthropometric measurements

Posted Date: June 8th, 2021

DOI: https://doi.org/10.21203/rs.3.rs-534002/v1

License: () (i) This work is licensed under a Creative Commons Attribution 4.0 International License. Read Full License 


\section{Abstract}

Introduction:

The purpose of the study conducted within the framework of the, "Let's Get the Kids Moving" project was to determine the association between longitudinal and transverse children's foot arch and their body mass, gender, and age.

Materials and method:

T he pro-health initiative "Let's Get the Kids Moving" was created by researchers of the Medical University and the Run for Health Foundation. A total of 655 children (51.5\% boys) aged 7 - 10 years from primary schools in southwestern Poland participated in the study. The mean age of the examined pupils was $8.7 \pm 0$.8 years. In all children, we assessed anthropometric measurements (body mass and height) and longitudinal and transverse arch of the foot under a load of their weight. A two-dimensional (2D) foot Scanner (Sensor Medica, Italy) was used to examine the plantar part of the pupils' foot.

Results:

The obtained data from 655 pupils revealed that excessive body mass predisposed to lower longitudinal and transverse arching. The foot shape was not differentiated by children's gender and age in the youngest age group.

Conclusions:

Screening of school-aged children's footprints allows for early detection of abnormalities in the shape of the pupil's feet. This enables the implementation of further early diagnosis for the detection of functional or structural flatfoot in children.

\section{Introduction}

The human foot is a complex static-dynamic structure holding the whole body mass. The foot core system consists of three subsystems (neural, active, and passive), which provide stability and flexibility indispensable for everyday life. Foot's appropriate functioning is depended on its proper shape and tension of two transverse and five longitudinal arching and morphological structure [1]. An efficient foot's core system is essential for the proper functioning of the foot. It allows the foot's adaptation to change structure and load conditions [2].

Foot parameters change during children's growth and puberty [3]. The feet' neuromuscular control also develops along with the increase in children's age [4]. Arch-forming structures are already beginning to shape in infants during spontaneous foot-grabbing activity. Up to the age of two, on the medial side from around the metatarsophalangeal toe to the talocalcaneonavicularis joint, the child's foot joint is filled with the so-called Spitzy's fat pad [2]. This fatty pad reduces the pressure per unit area of feet. From about two years of age, the medial foot arch begins to be noticeable in children. The fatty pad disappears until about the age of five and flat and/or valgus feet almost completely disappear up to the age of seven [5]. Girls reach medial longitudinal arching (MLA) stability earlier than boys [6].

The trend of the increasing prevalence of excessive body mass among children in Europe is observed [7], which may contribute to disproportional pressure on the midfoot area and MLA in standing position [3]. The structures of the musculoskeletal system in developmental age are not able to compensate for too heavy load [3]. Muscular disbalance of the feet might cause the restriction of children's participation in physical activity and a higher risk to develop excessive body mass [8]. Excessive body weight changes the foot loading during walking or running and may contribute to musculoskeletal deformity [9]. Slight musculoskeletal dysfunctions might contribute to the changes in the lower extremity bio kinematic chain. This could also apply to the foot's motility and disturbances in a body balance in the standing position [10].

\section{Objective}

The purpose of the study conducted within the framework of the, "Let's Get the Kids Moving" project was to assess the feet longitudinal and transverse arching of the pupils aged 7-10 years from primary schools in Wrocław, Poland. The pro-health initiative

"Let's Get the Kids Moving" was created by researchers of the Medical University and the Run for Health Foundation. Obtained results 
were correlated with the pupils' body mass, age, and gender. The Let's Get the Kids Moving" project aims at parents, children, and their teachers to promote a healthy lifestyle in children.

\section{Materials And Method}

Participants

Parents/legal guardians of children from five public primary schools in Wrocław, Poland, received written information about the study before the examination started. It was explained that participation in this study was voluntary and free. The inclusion criteria for the study were: written and informed parent's consent, age of children between 7 and 10 years, and primary school attendance. The written consent was obtained from 688 parents. The exclusion criteria of the study were: complicated lower extremity fracture in the past or present, serious musculoskeletal or neurologic diseases, congenital abnormalities of the feet, or any other chronic illness. The study group consisted of 655 children. The study excluded 33 children $(4.80 \%)$.

Ethical approval for the study was obtained from the Wrocław Medical University Bioethics Committee, Poland (approval no. KB738/2018). The study was conducted following the Declaration of Helsinki and The Strengthening Reporting of Observational Studies in Epidemiology (STROBE) recommendations.

Measurements

Body mass category

Pupils' weight and height were collected using an identical medical weight scale with a stadiometer in all five schools. Anthropometric measurements (weight and height) were carried out by physiotherapists in the place designated by the school management (a gymnastics hall or a classroom). The anthropometric measurements of every child were carried out individually. Data collection was carried out between March and June 2018 during school days. Measurements were taken in the morning between 8:00 AM and 1:30 PM. Each child during the examination was in light clothing and without shoes (in socks). Body mass weight was measured with an electronic medical scale (Charder MS 6110, Taiwan) with an accuracy of $0.1 \mathrm{~kg}$. The scales met the directives MDD 93/42 EEC in the field of medical devices. Children's height was measured using a Wall-Mounted Stadiometer (HM202P, Taiwan) and obtained results had an accuracy of $0.1 \mathrm{~cm}$.

Based on the measured body weight and height of the child, the nutritional status index (Cole's Index - $\mathrm{Cl}$ ) was calculated. The actual body weight and height were compared with the body weight and height read from centile grids (corresponding to 50 . centile for the age and sex of the child). The $\mathrm{Cl}$ level was as follows: underweight, normal body weight, overweight, and obesity $[11,12]$.

Foot anthropometrics

To examine the plantar part of the foot a two-dimensional (2D) FootCAD PodoScan (FreeMed, SensorMedica, Italy) was used. All obtained data was recorded with compatible FreeSTEP BASIC software (version 1.4.01) which allows making manual or automatic measurements. The FootCAD PodoScan dimensions were as follows: $623 \times 400 \times 133 \mathrm{~h}$ mm with maximal scanning area $(\mathrm{W} \times \mathrm{L})$ $304.8 \mathrm{~mm} \times 431.8 \mathrm{~mm}$. The scanning speed of each footprint was $8.5 \mathrm{sec}$. This device was fitted with a Charge Coupled Device (CCD) with a cold cathode, which guaranteed the high quality (optical resolution $1600 \mathrm{dpi}$ ) of the obtained footprint [13].

During the examination, the child stood on the PodoScan surface both bare feet with full weight-bearing in an upright position looking straight ahead. The next step after scanning the feet was the manual evaluation of medial longitudinal and transverse arches in FreeSTEP BASIC software. To identify the MLA have used the following indicators:

- Clarke's angle (CL angle) - it is an angle between a tangent to the medial edge of the foot (the most extreme point on the head of the first metatarsal bone (metatarsale tibiale) - point mtt and at the medial edge of the heel - point A) and a line connecting the deeper forefoot part of the footprint (point B) with point $\mathrm{mtt}$. CL angle is expressed in degrees [0].

- Sztriter - Godunov index (K-y index) - determines the ratio of the length of the shaded part of the footprint (line CD) to the length of the shaded and not shaded part of the footprint (line BD). K-y index is measured at the height of the center of the MLA.

To identify the transverse arch the following indicator was used:

Page $3 / 12$ 
-Wejsflog index ( $W$ index) - it is a ratio of the length (a line from the longest toe - point $E$ to the extreme point of the heel - point $F$ ) to the width (a line from point $\mathrm{mtt}$ to the most extreme point on the head of the fifth metatarsal bone (metatarsale fibulare) - point $\mathrm{mtf}$ ) of the foot (Figure 1).

Data Analysis

Statistical analysis was performed using Dell Statistica 13.1 (TIBCO Software Inc, United States). Descriptive static was presented as mean values, standard deviation (SD), median (Med), ranges of variation (minimal - Min. and maximum - Max. value), interquartile range (lower $-Q_{1}$ and upper quartile $Q_{3}$ ). Categorical variables were calculated as frequencies (percentages). Normal distribution was determined using the Kolmogorov-Smirnov test. The parametric t-test was used to compare the two groups in terms of the mean level of the quantitative variable. One-way analysis of variance (ANOVA) was used to compare 3 or more groups in terms of the mean level of the quantitative variable. When the p-value was below .05 post-hoc analysis (Tukey's test) was used. For data whose distribution differed from the normal distribution, the non-parametric Mann - Whitney $U$ test (for 2 groups) and Kruscal - Wallis test (for 3 and more groups) were used. The association between the selected variables was determined by the Spearman rank correlation test. The statistical significance level was set at $p<0.05$ for all comparisons.

\section{Results}

The "Let's Get the Kids Moving" study included 337 boys and 318 girls. The mean age of the examined pupils was 8.7 years. The proportion of children in each $\mathrm{Cl}$ level in our examined sample was as follows: underweight, $27.17 \%(\mathrm{~N}=178)$; normal body weight, $51.14 \%(\mathrm{~N}=335)$; overweight, $11.60 \%(\mathrm{~N}=76)$; obesity, 10.07\% ( $\mathrm{N}=66)$. Table 1 presents the characteristics of studied children concerning gender, age, and $\mathrm{Cl}$ category. The characteristics of the quality variables of the sample of 655 pupils are shown in Table 2.

Longitudinal and transverse arches value of children foot

A tendency to have higher mean K-y index value for left $(L)(0.41 \pm 0.21$ vs. $0.37 \pm 0.20 ; p=0.0129)$ and right $(R)$ foot $(0.41 \pm 0.20$ vs. $0.38 \pm 0.18 ; p=0.0053$ ) was noted in more boys than girls, respectively (Table 3 ). There was no significant difference between boys and girls and mean value of $C L$ angle and $W$ index for $L$ and $R$ foot, respectively $(p>0.05)$.

A statistically significant difference in the mean $C L$ angle value for $L$ foot in terms of $C l$ level was observed $(p<0.0001)(T a b l e ~ 4)$. The detailed analysis established significant variation in mean $C L$ angle value for $L$ foot between underweight and obese children ( $p=$ $0.0003)$, and between children with normal weight and children with obesity $(p=0.0114)$. There were no significant differences in the mean $\mathrm{CL}$ angle value for $\mathrm{R}$ foot in terms of $\mathrm{Cl}$ level $(\mathrm{p}>0.05)$ (Table 4$)$.

There was a statistically significant variation in the mean $\mathrm{K}-\mathrm{y}$ index value in terms of $\mathrm{Cl}$ category of the $\mathrm{L}(\mathrm{p}=0.0026)$ and $R$ foot $(p=$ 0.0024), respectively (Table 4). A more detailed analysis with the post-hoc test revealed differences in mean K-y index value of the $L$ foot between underweight and children with obesity $(p=0.0012)$, and between normal weight and children with obesity $(p=0.0581)$. The variation of mean K-y index for the $L$ foot between normal weight (mean K-y index: $0.40 \pm 0.20$ ) and children with obesity (mean $\mathrm{K}-\mathrm{y}$ index: $0.48 \pm 0.18)$ was on the threshold of statistical significance level $(p=0.0581)$. A statistically significant difference in $\mathrm{K}-\mathrm{y}$ index value for the $R$ foot between underweight and children with obesity ( $p=0.0012)$, and between normal weight and children with obesity ( $p=0.0319)$ was observed. A positive very high correlation between mean $K-y$ index value for $L$ and $R$ foot $($ rho $=0.78 ; p<0.05)$ was shown.

In underweight children, the mean $W$ index value for $L$ foot was significantly higher than among children with normal weight $(p=$ $0.0083)$, overweight $(p=0.0006)$, and obesity $(p=0.0018)$. A similar statistical significance was found regarding the mean $W$ index value for the $\mathrm{R}$ foot and $\mathrm{Cl}$ category $(\mathrm{p}<0.0001)$. Underweight children had significantly higher mean $\mathrm{W}$ index value for $\mathrm{R}$ foot than their peers with normal weight $(p=0.0118)$, overweight $(p=0.0006)$ and obesity $(p=0.0013)$ (Table 4$)$.

No significant differences were found ( $p>0.05$ ) between pupils' age and $C L$ angle for $L$ foot, $K$-y index for $L$ and $R$ foot, $W$ index for $L$ and $R$ foot. The statistical differences between children's age and $C L$ angle for $R$ foot were revealed $(p<0.0008)$ (Table 5). More detailed analysis indicated differences in CL angle for $R$ foot between 7 and 8 years old $(p=0.0390), 7$ and 10 years old $(p=0.0007)$, and 9 and 10 years old children $(p=0.0449)$. 
In our study, we did not observe a statistically significant correlation between children's age and MLA and transverse foot arch, except for the $\mathrm{CL}$ angle for $\mathrm{R}$ foot. A weak positive correlation ( $r h o=0.1094 ; p<0.05$ ) was showed between the $C L$ angle for $\mathrm{R}$ foot and pupils' age.

\section{Discussion}

In recent years, numerous studies from different countries raise the interest of the pediatric foot in relation to the weight category [9,14-16]. Uden et al. [17] in a systematic review of 34 studies analyzing pediatric foot, highlighted that modern research lacks uniform guidelines for assessment foot posture. Many authors took up in their examination the aspect of children's excessive body mass and feet arches [4,9,14,18-20]. Nevertheless, few researchers had included in their analysis a group of underweight children [8]. Mauch et al.[8] observed that children with underweight had longer and slenderer fees than children with normal and excessive body weight.

Mauch et al.[8] in the study conducted in 2887 pupils observed that flat feet were more common in overweight children. Jankowicz Szymańska et al. [19] in a cross-sectional study conducted in 1377 preschool children, observed that Clarke's angle value was associated with the weight category. The authors established that in children with normal body mass the MLA was the highest. Children aged between 3 and 7 years who demonstrated excessive body mass had an elevated risk of developing flat feet than their peers with normal body mass [19]. Maciałczyk-Paprocka et al. [18] in a study among 2732 children found similar correlations. Children between the ages of 3 to 18 years with obesity were predisposed to flat feet.

Comparable to our results, other authors $[16,21]$ showed that in children with excessive body mass flatter MLA is more prevalent than in their peers with normal body weight. The findings from a study performed on 550 Egyptian school children showed that obese pupils were 6.1 times more likely to have a flat foot and 8.5 times more likely to experience foot pain [22]. Overweight and children with obesity with flat foot have a higher level of adipocytes cytokinesis than their peers with normal weight status [22]. SadeghiDemneh et al. [4] in a group of 667 children aged from 7 to 14 years showed that children with obesity more often than their peers with the normal body weight felt foot pain during participation in physical activity. Woźniacka et al. [15] showed that a higher association between MLA and obesity was found among female pupils.

Our findings in line with other studies $[5,6,20]$ showed that MLA was not dependent on the pupils' age in early school-aged children. On the other hand, in our research CL angle for R foot statistically significant, increased along with pupil's age. This tendency of completed formation of foot arch structure was also confirmed by Hazzaa et al. [20] in a group of children with obesity aged between 8-14 years.

Contrary to other researchers' results $[16,20,23]$ in our and Tong et al. [6] study no statistically significant differences in CL angle parameters were showed between boys and girls. Chang et al.[16] a cross-sectional study conducted on 2083 children between 7 and 12 years of age from Taiwan observed that boys had a 2-fold higher tendency to flatfoot than girls. Hazzaa et al. [20] in a study among 150 obese children observed that boys had flat feet significantly more often than girls. Our results showed that boys had a higher mean K-y index level than girls. Puszczałowska-Lizis et al. [23] revealed that girls had a higher mean CL angle level than boys. Delgado-Abelan et al. [24] in a study among 1033 Spanish school-aged children observed that foot dimensions differed between girls and boys at the age of eight years. Different results might have been associated with the use of various research tools and indexes for assessing flat feet in children.

Cobb et al. [25] emphasized that Clarke's angle value had an impact on postural stability. They observed correlations between arch posture and mediolateral postural stability during a one-extremity stance. Gijon-Nogueron et al. [26] in a study among 316 school children from Spain revealed a high negative correlation between foot posture index and Clarke's angle. Similar results were obtained by Brzezińska et al.[27] in their large cohort study of 6992 children aged from 8 to 12 years old. They revealed that childhood obesity and overweight were connected with the occurrence of lower limb postural defects. Feet of children with overweight and obesity had closer contact with the ground than feet of their peers with normal body weight [28]. Children's body mass index (BMI) was negatively correlated with the center of foot pressure (COP) [10]. Szczepanowska-Wołowiec et al. [10] showed a statistically significant weak correlation between the $\mathrm{CL}$ angle of the $\mathrm{R}$ foot and length and surface area of COP.

Other factors might also affect the risk of the occurrence of the lowered arch in the children's feet. Tong et al. in a study carried out in 111 healthy children with a mean age of 6.9 years old, showed that children who walked in slippers at a younger age had a flatter 
MLA at a later stage of their development than children who used sandals [6]. Cetin et al. [21] in research in 625 pupils between 6 and 13 years old in Anatolia observed that the occurrence of flat feet in children was related to the place of residence and familiar history of flat feet.

One of the methods to improve the shape arching of the feet is short foot exercise training. A short foot exercise (SFE) is a type of special exercise that is the basis for proprioceptive training of the foot. Systematical participation in the SFE program might increase MLA and improve functional balance. The main purpose of SFE training is to practice internal foot muscle contractions during different functional tasks with increasing difficulty [29]. The aim of muscular foot training during walking is to increase the amount of collagen in the tendons and ligaments of the feet. This process increases the strength of the feet muscles.

Future Research

Researchers from our team have recognized the need for a study in a larger population to assess the morphology of children's feet compared to their parents. In November 2020 we started the Population CohorT StUdy of Wroclaw CitizEns (PICTURE) project. It is planned for 2500 participants. In PICTURE we take into account the re-examination after two years from the first examination. Particular attention should be paid to shape changes in the arches of children with excessive body weight.

Limitations

Limitations of the study include a lack of data on musculoskeletal symptoms among children overweight and obese with a lowered foot arch. A further limitation was the limited number of participants taking part in the study.

\section{Conclusions}

Childhood obesity and overweight is one of the factors lowering the longitudinal and transverse foot arching. The prevention of childhood obesity might contribute to reducing pain in the musculoskeletal system in adulthood. Children with excessive body mass should be encouraged to undertake physical activity during which weakened muscles of the foot might be strengthened. When conducting a screening examination to assess children's body posture, the researchers ought to look at each child holistically and analyze the entire body posture parameters and weight status, not just foot measurements. Examination of every child suspected of having abnormalities in the arches of the foot should additionally consist of functional tests to check the muscular capacity of the child's foot.

\section{Abbreviations}

CCD: Charge Coupled Device; CL: Clarke's angle; Cl: Cole's Index; K-y index: Sztriter-Godunov index; L: left: Max.: maximum value; MDD: Medical Device Directive; Med: median; Min.: minimal value; MLA: medial longitidinal arching; mtf: metatarsale fibulare; mtt: metatarsale tibiale; PICTUE: Population Cohort Study of Wroclaw Citizens; $\mathrm{Q}_{1}$ : lower quartile; $\mathrm{Q}_{3}$ : upper quartile R: right; SD: standard deviation; SFE: short foot exercise; STORBE: The Strengthening Reporting of Observational Studies in Epidemiology; W index: Wejsflog index;

\section{Declarations}

\section{Acknowledgements}

The program promoting a healthy lifestyle "Let's Get the Kids Moving" has been supported by the Department of Education of the Municipal Office of Wrocław and "The Light Backpack" foundation. The authors would like to thank school headmasters, teachers, and parents for taking part in the project.

Competing interests

The authors declare that they have no competing interests.

Ethics approval and consent to participate 
Ethical approval for the study was obtained from the Wrocław Medical University Bioethics Committee, Poland (approval no. KB738/2018). The study was conducted following the Declaration of Helsinki and The Strengthening Reporting of Observational

Studies in Epidemiology (STROBE) recommendations.

Consent for publication: Not applicable

Availability of data and materials: Please contact author for data requests.

Funding: Not applicable

Authors' contributions:

SG conceived of the study, drafted the manuscript.

KPZ: took part in coordination and helped to draft the manuscript

ABR: took part in coordination and helped to draft the manuscript

JK: took part in coordination and helped to draft the manuscript

MK: took part in coordination and helped to draft the manuscript

TZ participated in the design of the study, took part in coordination and helped to draft the manuscript and performed the statistical analysis.

Conflict of Interest statement: The authors declare no conflict of interest.

Grant support: none

\section{References}

1. McKeon PO, Hertel J, Bramble D, Davis I. The foot core system: a new paradigm for understanding intrinsic foot muscle function. Br J Sport Med. 2015; 49(5),290. https://doi.org/10.1136/bjsports-2013-092690.

2. Nurzyńska D, Di Meglio F, Latino F, Romano V, Miraglia R, Guerra G, et al. Flatfoot in children: anatomy of decision making. Italian Journal of Anatomy and Embryology. 2012;117(2):98-106.

3. Mueller S, Carlsohn A, Mueller J, Baur H, Mayer F. Influence of Obesity on Foot Loading Characteristics in Gait for Children Aged 1 to 12 Years. PLoS ONE. 2016; 11(2):e0149924. https://doi.org/10.1371/journal.pone.0149924.

4. Sadeghi-Demneh E, Azadinia F, Jafarian F, Shamsi F, Melvin JM, at al. Flatfoot and obesity in school-age children: a crosssectional study. Clin Obes. 2016;6:42-50. https://doi.org/10.1111/cob.12125.

5. Coppello T, Song KM. Determining treatment of flatfeet in children. Curr Opin Pediatr. 1998;10(1):77. https://doi.org/10.1097/00008480-199802000-00016.

6. Tong JWK, Kong PW. Medial Longitudinal Arch Development of Children Aged 7 to 9 Years: Iongitudinal Investigation. Phys Ther. 2016; 96:1216-24. https://doi.org/10.2522/ptj.20150192.

7. Ahrens W, Pigeot I, Pohlabeln H, De Henauw S, Lissner L, Molnar D, et al. Prevalence of overweight and obesity in European children below the age of 10. Int J Obes. 2014;38:S99-107. https://doi.org/10.1038/ijo.2014.140.

8. Mauch M, Grau S, Krauss C, Maiwald C, Horstmann T. Foot Morphology of Normal, Underweight and Overweight Children. Int J Obes. 2008; 32(7):1068-75. https://doi.org/10.1038/ijo.2008.52.

9. Cousins SD, Morrison SC, Drechsler WI. Foot loading patterns in normal weight, overweight and obese children aged 7 to 11 years. J Foot Ankle Res. 2013; 6:1-1. https://doi.org/10.1186/1757-1146-6-36.

10. Szczepanowska-Wołowiec B, Sztandera P, Kotela I, Żak M. Feet deformities and their close association with postural stability deficits in children aged 10-15 years. BMC Musculoskeletal Disorders. 2019; 20:537. https://doi.org/10.1186/s12891-019-29233. 
11. Cole TJ. Body mass index cut offs define thinness in children and adolescents: international survey. BMJ. $2007 ; 335: 194-201$. https://doi.org/10.1136/bmj.39238.399444.55.

12. Cole TJ, Bellizzi MC, Flegal KM, Dietz WH. Establishing a standard definition for child overweight and obesity worldwide: international survey. BMJ. 2000; 6:1240-1243. https://doi.org/10.1136/bmj.320.7244.1240.

13. Podoscan 2D. https://www.sensormedica.com/en/. (access:2020.11.05).

14. Morrison SC, McCarthy D, Hahaffey R. Associations between obesity and paediatric foot dimensions. J Am Podiatr Med Assoc. 2018; 108(5):383-89.

15. Woźniacka R, Bac A, Matusik S, Szczygieł E, Ciszek E. Body weight and the medial longitudinal foot arch: high-arched foot, a hidden problem? Eur J Pediatr. 2013; 172:683-91. https://doi.org/10.1007/s00431-013-1943-5.

16. Chang J-H, Wang S-H, Kuo C-L, Shen HC, Hong Y-W, Lin L-C. Prevalence of Flexible Flatfoot in Taiwanese School-Aged Children in Relation to Obesity, Gender, and Age. Eur J Pediatr. 2010; 169(4):447-52. https://doi.org/10.1007/s00431-009-1050-9.

17. Uden H, Scharfbillig R, Causby R. The Typically Developing Paediatric Foot: How Flat Should It Be? A Systematic Review. J Foot Ankle Res. 2017; 10:37. https://doi.org/10.1186/s13047-017-0218-1.

18. Maciałczyk-Paprocka K, Stanińska-Witoszyńska B, Kotwicki T, Sowińska A, Krzyżaniak A, Walkowiak J, et al. Prevalence of incorrect body posture in children and adolescents with overweight and obesity. Eur J Pediatr. 2017; 176:563-572. https://doi.org/10.1007/s00431-017-2873-4.

19. Jankowicz-Szymańska A, Mikołajczyk E. Genu Valgum and Flat Feet in Children With Healthy and Excessive Body Weight. Pediatr Phys Ther. 2016; 28(2):200-6. https://doi.org/10.1097/PEP.0000000000000246.

20. Hazzaa HH, El-Meniawy GM, Ahmed SE, Bedier MB. Correlation between gender and age and flat foot in obese children. Trends Appl Sci Res. 2015; 10(4),207-15.

21. Cetin A, Sevil S, Karaoglu L, Yucekaya B. Prevalence of flat foot among elementary school students in rural and urban areas and at suburbs in Anatolia. Eur J Orthop Surg Traumatol. 2011; 21,327-31.

22. Alghadir AH, Gabr SA, Rizk AA. Plasmatic adipocyte biomarkers and foot pain associated with flat foot in school children with obesity. Rev Assoc Med Bras. 2019; 65(8):1061-6. https://doi.org/10.1590/1806-9282.65.8.1061.

23. Puszczałowska-Lizis E, Ridan T, Ogarek M. Characteristics parameters of the longitudinal and transverse arch of feet in girls and boys in the early-school period. Young Sport Science of Ukraine. 2011; 3:234-39.

24. Delgado-Abellan L, Aguado X, Jimenez-Ormeno E, Mecerreges L, Algre LM. Foot morphology in Spanish school children according to sex and age. Ergonomics. 2014; 57(5):787-97. https://doi.org/10.1080/00140139.2014.895055.

25. Cobb SC, Bazett-Jones DM, Joshi MN, Earl-Boehm JE, James CR. The relationship among foot posture, care and lower extremity muscle function, and postural stability. J Athl Train. 2014;49(2):173-80. https://doi.org/10.4085/1062-6050-49.2.02.

26. Gijon-Nogueron G, Marchena-Rodriguez A, Montes-Alguacil J, Evans AM. Evaluation of the Paediatric Foot Using Footprints and Foot Posture Index: A Cross-Sectional Study. J Paediatr Child Health. 2020; 56(2):201-6. https://doi.org/10.1111/jpc.14558.

27. Brzeziński M, Czubek Z, Niedzielska A, Jankowski M, Kobus T, et al. Relationship between lower-extremity defects and body mass among polish children: a cross-sectional study. BMC Musculoskeletal Disorders. 2019; 20:84.

https://doi.org/10.1186/s12891-019-2460-0.

28. Mueller S, Carlsohn A, Mueller J, Baur H, Mayer F. Static and dynamic foot characteristic in children aged 1-13 years: a crosssectional study. Gait Posture. 2012; 35:389-394. https://doi.org/10.1016/j.gaitpost.2011.10.357.

29. Mulligan EP, Cook PG. Effect of plantar intrinsic muscle training in medical longitudinal arch morphology and dynamic function. Man Ther. 2013; 18:425-30. https://doi.org/1016/j.math.2013.02.007.

\section{Tables}

Table 1. Descriptive characteristic of studied children 


\begin{tabular}{|ll|}
\hline Variables & $\mathrm{n}(\%)$ \\
\hline Gender & \\
\hline Boys & $337(51.45)$ \\
\hline Girls & $318(48.55)$ \\
\hline Age [years] & \\
\hline 7 & $28(4.27)$ \\
\hline 8 & $232(35.42)$ \\
\hline 9 & $280(42.75)$ \\
\hline 10 & $115(17.56)$ \\
\hline Cole's index category & \\
\hline Underweight & $178(27.17)$ \\
\hline Normal body weight & $335(51.14)$ \\
\hline Overweight & $76(11.60)$ \\
\hline Obesity & $66(10.07)$ \\
\hline
\end{tabular}

Table 2. Clinical characteristics for children

\begin{tabular}{|c|c|c|c|c|c|}
\hline Variables & Mean $\pm S D$ & Min.-Max. & $\mathrm{Q}_{25}$ & $\mathrm{Me}$ & $\mathrm{Q}_{75}$ \\
\hline Age [years] & $8.74 \pm .79$ & $7-10$ & 8 & 9 & 9 \\
\hline Body weight [kg] & $29.99 \pm 6.83$ & $17.4-63$ & 25.2 & 28.6 & 33.6 \\
\hline Body height [cm] & $134.51 \pm 7.15$ & $114.5-157$ & 129.4 & 134 & 139.5 \\
\hline $\mathrm{Cl}[\%]$ & $100.0 \pm 15.6$ & $70.7-184$ & 89.2 & 96.4 & 107.9 \\
\hline $\mathrm{CL}$ ankle $\mathrm{L}$ foot $\left[^{\circ}\right]$ & $46.60 \pm 9.71$ & $50-76$ & 41 & 46 & 53 \\
\hline CL ankle $\mathrm{R}$ foot ${ }^{\circ}{ }^{\circ}$ & $47.53 \pm 8.71$ & $4-76$ & 42 & 48 & 53 \\
\hline$K-y$ index L foot & $0.39 \pm 0.21$ & $0-1$ & 0.32 & 0.43 & 0.52 \\
\hline K-y index R foot & $0.39 \pm 0.19$ & $0-1$ & 0.32 & 0.43 & 0.50 \\
\hline$W$ index $L$ foot & $2.78 \pm 0.16$ & $2.3-3.23$ & 2.67 & 2.78 & 2.89 \\
\hline W index $R$ foot & $2.78 \pm 0.16$ & $2.31-3.20$ & 2.68 & 2.78 & 2.89 \\
\hline
\end{tabular}

Abbreviations: SD, standard deviation; Min., minimum value; Max., maximum value; $Q_{25}$, lower quartile; Me, median; $Q_{75}$, upper quartile $\mathrm{Cl}$, Cole's Index; CL, Clark; L, left; R, right; K-y, Sztriter-Godunov; W, Wejsflog

Table 3. Clarke's angle, Sztriter-Godunov index and Wejsflog index levels comparisons by gender 


\begin{tabular}{|c|c|c|c|c|c|c|c|c|c|c|c|c|}
\hline \multirow[b]{2}{*}{ Gender } & \multicolumn{6}{|l|}{$L$ foot } & \multicolumn{6}{|l|}{$R$ foot } \\
\hline & Mean $\pm S D$ & $\begin{array}{l}\text { Min.- } \\
\text { Max. }\end{array}$ & $\mathrm{Q}_{1}$ & $\mathrm{Me}$ & $\mathrm{Q}_{3}$ & $\begin{array}{l}\mathrm{p}- \\
\text { value }\end{array}$ & Mean $\pm S D$ & $\begin{array}{l}\text { Min.- } \\
\text { Max. }\end{array}$ & $\mathrm{Q}_{1}$ & $\mathrm{Me}$ & $\mathrm{Q}_{3}$ & $\mathrm{p}$-value \\
\hline & \multicolumn{12}{|l|}{ Clarke's angle } \\
\hline Boys & $46.73 \pm 10.23$ & $8-74$ & 41 & 47 & 53 & \multirow[t]{2}{*}{0.4068} & $47.35 \pm 9.31$ & $4-76$ & 42 & 48 & 53 & \multirow[t]{2}{*}{0.9180} \\
\hline \multirow[t]{2}{*}{ Girls } & $46.50 \pm 9.05$ & $5-76$ & 41 & 46 & 52 & & $47.75 \pm 7.89$ & $23-73$ & 42 & 47 & 52 & \\
\hline & \multicolumn{12}{|c|}{ Sztriter-Godunov index } \\
\hline Boys & $0.41 \pm 0.21$ & $0-1$ & 0.34 & 0.21 & 0.54 & \multirow[t]{2}{*}{0.0129} & $0.41 \pm 0.20$ & $0-1$ & 0.35 & 0.45 & 0.52 & \multirow[t]{2}{*}{$0.0053^{\mathrm{s}}$} \\
\hline \multirow[t]{2}{*}{ Girls } & $0.37 \pm 0.20$ & $0-1$ & 0.30 & 0.42 & 0.50 & & $0.38 \pm 0.18$ & $0-0.84$ & 0.31 & 0.41 & 0.49 & \\
\hline & \multicolumn{12}{|c|}{ Wejsflog index } \\
\hline Boys & $2.79 \pm 0.17$ & $\begin{array}{l}2.30- \\
3.20\end{array}$ & 2.65 & 2.76 & 2.87 & \multirow[t]{2}{*}{0.0449} & $2.77 \pm 0.16$ & $\begin{array}{l}2.31- \\
3.20\end{array}$ & 2.67 & 2.78 & 2.88 & \multirow[t]{2}{*}{0.1046} \\
\hline Girls & $2.79 \pm 0.15$ & $\begin{array}{l}2.43- \\
3.23\end{array}$ & 2.69 & 2.78 & 2.91 & & $2.79 \pm 0.15$ & $\begin{array}{l}2.41- \\
3.19\end{array}$ & 2.69 & 2.79 & 2.89 & \\
\hline
\end{tabular}

Abbreviations: SD, standard deviation; Min., minimum value; Max., maximum value; $Q_{25}$, lower quartile; Me, median; $Q_{75}$, upper quartile; L, left; $R$, right.

s Statistical significance differences $p<0.05$

Table 4. Clarke's angle, Sztriter-Godunov index and Wejflog index levels comparisons by Cl category 


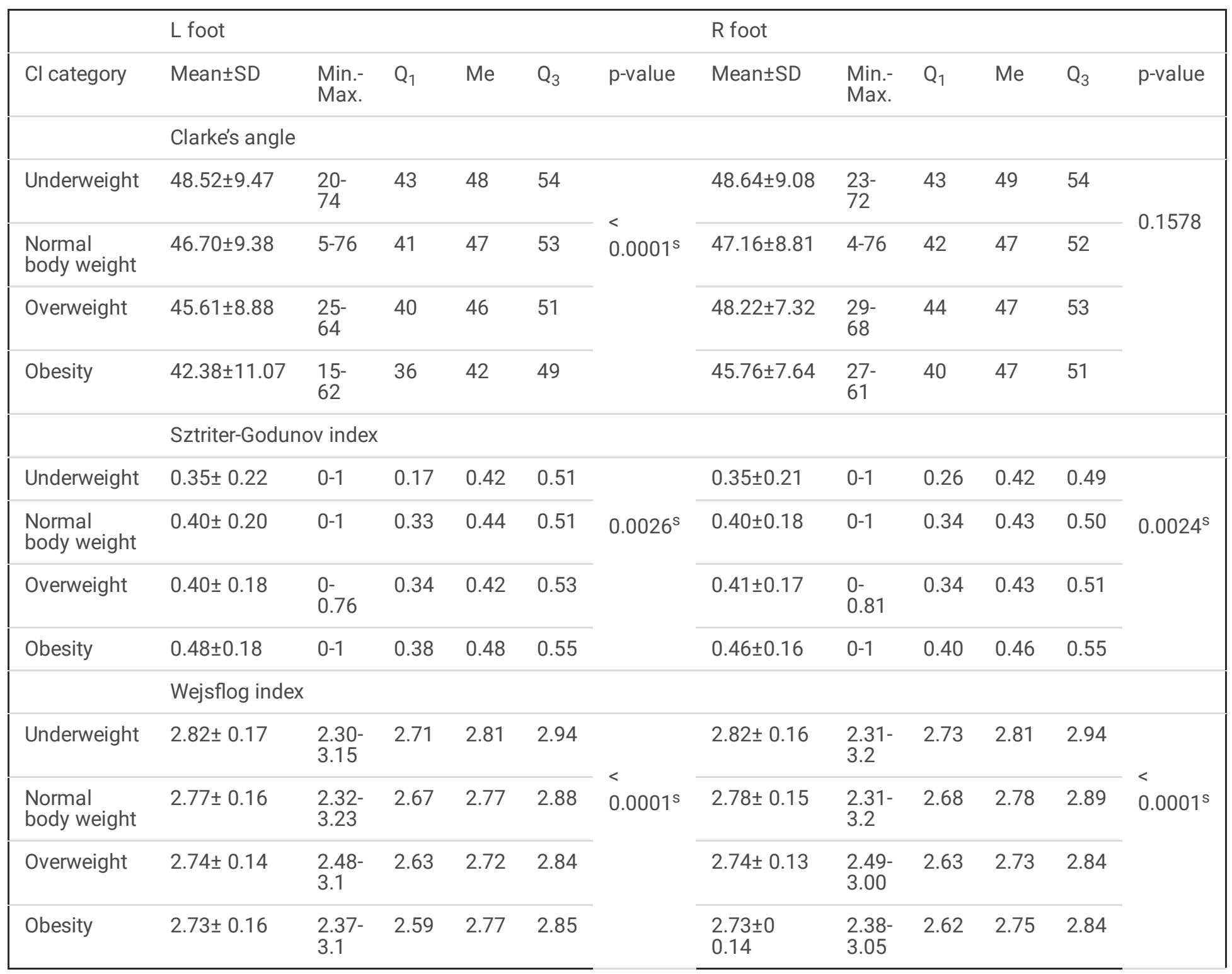

Abbreviations: SD, standard deviation; Min., minimum value; Max., maximum value; $Q_{25}$, lower quartile; Me, median; $Q_{75}$, upper quartile; L, left; R, right.

s Statistical significance differences $p<0.05$

Table 5. Clarke's angle, Sztriter-Godunov index and Wejsflog index levels comparisons by children's age 


\begin{tabular}{|c|c|c|c|c|c|c|c|c|c|}
\hline \multirow[t]{2}{*}{ Variables } & \multicolumn{2}{|l|}{7 year olds } & \multicolumn{2}{|l|}{8 year olds } & \multicolumn{2}{|l|}{9 year olds } & \multicolumn{2}{|l|}{10 year olds } & \multirow[t]{2}{*}{$\mathrm{p}$-value } \\
\hline & Mean $\pm S D$ & $\begin{array}{l}\text { Min.- } \\
\text { Max. }\end{array}$ & Mean $\pm S D$ & $\begin{array}{l}\text { Min.- } \\
\text { Max. }\end{array}$ & Mean $\pm S D$ & $\begin{array}{l}\text { Min.- } \\
\text { Max. }\end{array}$ & Mean $\pm S D$ & $\begin{array}{l}\text { Min.- } \\
\text { Max. }\end{array}$ & \\
\hline $\begin{array}{l}C L \text { angle }-\mathrm{L} \\
\text { feet }\end{array}$ & $43.59 \pm 11.23$ & $8-66$ & $47.43 \pm 10.22$ & $9-76$ & $46.03 \pm 9.08$ & $5-74$ & $46.99 \pm 9.66$ & $15-69$ & 0.1199 \\
\hline $\begin{array}{l}C L \text { angle }-\mathrm{R} \\
\text { feet }\end{array}$ & $42.07 \pm 11.04$ & $9-60$ & $47.43 \pm 9.32$ & $4-73$ & $47.29 \pm 7.99$ & $19-76$ & $49.55 \pm 7.96$ & $27-69$ & $0.0008^{s}$ \\
\hline $\begin{array}{l}\text { K-y index - L } \\
\text { feet }\end{array}$ & $0.39 \pm 0.23$ & $0-0.94$ & $0.40 \pm 0.20$ & $0-1$ & $0.39 \pm 0.20$ & $0-1$ & $.40 \pm .21$ & $0-1$ & 0.7094 \\
\hline $\begin{array}{l}\text { K-y index - R } \\
\text { feet }\end{array}$ & $0.40 \pm 0.23$ & $0-0.80$ & $0.40 \pm 0.18$ & $0-1$ & $0.39 \pm 0.19$ & $0-1$ & $.40 \pm .19$ & $0-1$ & 0.9195 \\
\hline $\begin{array}{l}\text { W index - L } \\
\text { feet }\end{array}$ & $2.81 \pm 0.19$ & $\begin{array}{l}2.54- \\
3.18\end{array}$ & $2.77 \pm 0.16$ & $\begin{array}{l}2.32- \\
3.23\end{array}$ & $2.78 \pm 0.16$ & $\begin{array}{l}2.30- \\
3.20\end{array}$ & $2.79 \pm 0.16$ & $\begin{array}{l}2.35- \\
3.15\end{array}$ & 0.7349 \\
\hline $\begin{array}{l}\text { W index - R } \\
\text { feet }\end{array}$ & $2.81 \pm 0.19$ & $\begin{array}{l}2.45- \\
3.20\end{array}$ & $2.78 \pm 0.16$ & $\begin{array}{l}2.31- \\
3.17\end{array}$ & $2.78 \pm 0.15$ & $\begin{array}{l}2.31- \\
3.20\end{array}$ & $2.79 \pm 0.16$ & $\begin{array}{l}2.45- \\
3.19\end{array}$ & 0.7221 \\
\hline
\end{tabular}

Abbreviations: SD, standard deviation; Min., minimum value; Max., maximum value; $\mathrm{Q}_{25}$, lower quartile; Me, median; $\mathrm{Q}_{75}$, upper quartile; L, left; R, right.

s Statistical significance differences $p<0.05$

\section{Figures}

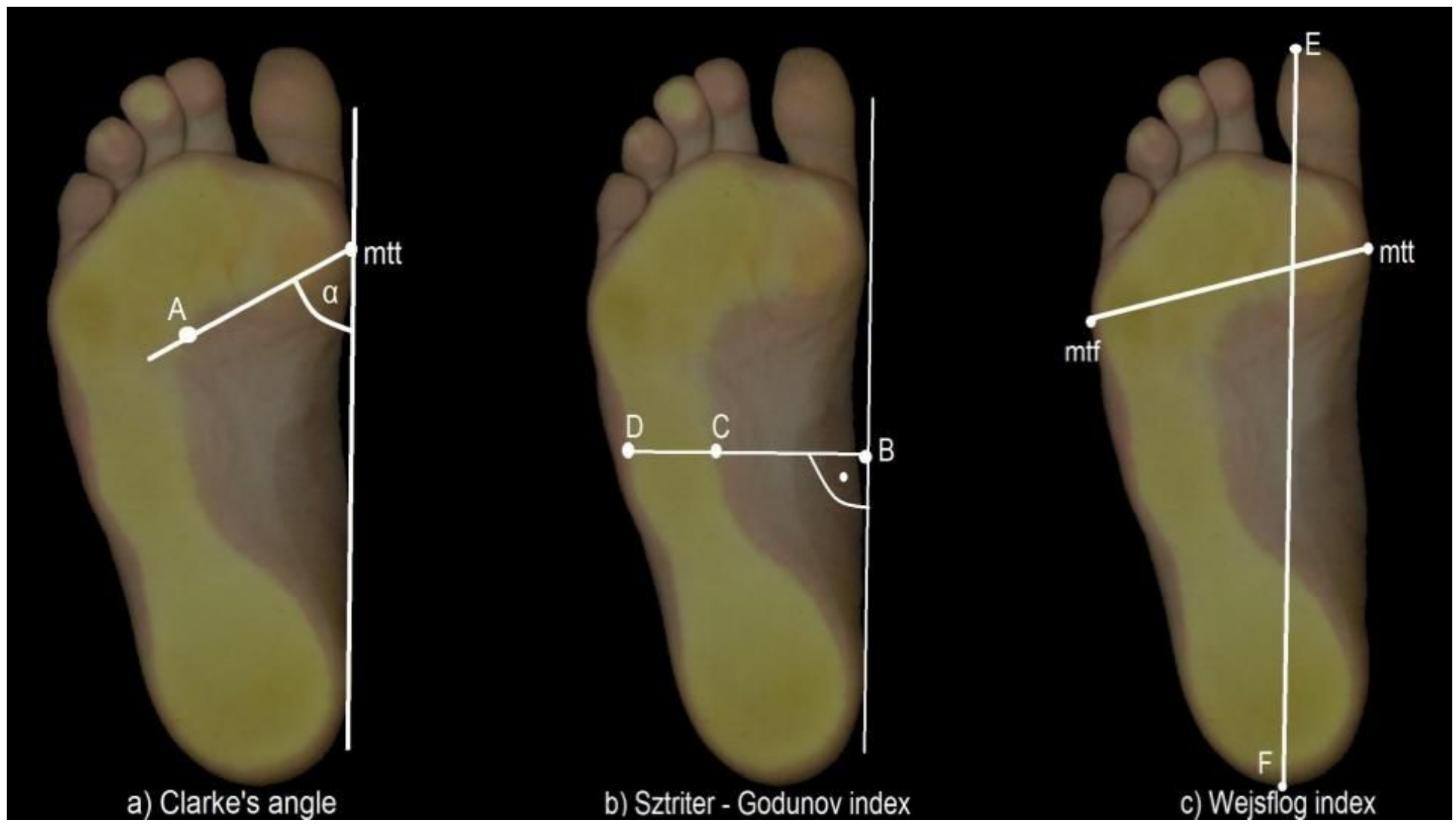

\section{Figure 1}

The method of determining the foot indicators on 2D footprint: a) Clarke's angle, b) Sztriter-Godunov index, c) Wejsflog index. Source: Footprint obtained from 2D FootCAD PodoScan. 